\title{
Review
}

\section{Auxinic herbicides, mechanisms of action, and weed resistance: A look into recent plant science advances}

\author{
Pedro Jacob Christoffoleti ${ }^{*}$, Marcelo Rodrigues Alves de Figueiredo ${ }^{1}$, Lázaro Eustáquio Pereira Peres², Scott Nissen ${ }^{3}$, Todd \\ Gaines $^{3}$
}

\author{
'University of São Paulo/ESALQ - Dept. of Crop Science, \\ C.P. 09 - 13418-900 - Piracicaba, SP - Brazil. \\ 2University of São Paulo/ESALQ - Dept. of Biological \\ Sciences. \\ ${ }^{3}$ Colorado State University/College of Agriculture Sciences \\ - Dept. of Bioagricultural Sciences and Pest Management, \\ 1177 Campus Delivery - 80523 - Fort Collins - Colorado \\ - USA. \\ *Corresponding author <pjchrist@usp.br>
}

Edited by: Paulo Cesar Sentelhas

Received October 13, 2014

Accepted February 25, 2015

\begin{abstract}
Auxin governs dynamic cellular processes involved at several stages of plant growth and development. In this review, we discuss the mechanisms employed by auxin in light of recent scientific advances, with a focus on synthetic auxins as herbicides and synthetic auxin resistance mechanisms. Two auxin receptors were reported. The plasma membrane receptor ABP1 (Auxin Binding Protein 1) alters the structure and arrangement of actin filaments and microtubules, leading to plant epinasty and reducing peroxisomes and mitochondria mobility in the cell environment. The second auxin receptor is the gene transcription pathway regulated by the $\mathrm{SCF}^{\mathrm{Ti} / \mathrm{AFB}}$ ubiquitination complex, which destroys transcription repressor proteins that interrupt Auxin Response Factor (ARF) activation. As a result mRNA related with Abscisic Acid (ABA) and ethylene are transcribed, producing high quantities of theses hormones. Their associated action leads to high production of Reactive Oxygen Species (ROS), leading to tissue and plant death. Recently, another ubiquitination pathway which is described as a new auxin signaling route is the F-box protein S-Phase Kinase-Associated Protein 2A (SKP2A). It is active in cell division regulation and there is evidence that auxin herbicides can deregulate the SKP2A pathway, which leads to severe defects in plant development. In this discussion, we propose that SFC ${ }^{\text {KKP2A }}$ auxin binding site alteration could be a new auxinic herbicide resistance mechanism, a concept which may contribute to the current progress in plant biology in its quest to clarify the many questions that still surround auxin herbicide mechanisms of action and the mechanisms of weed resistance. Keywords: TIR/AFB, SKP2A, Auxin binding protein 1, Reactive Oxygen Species transgenic crops
\end{abstract}

\section{Introduction}

Auxin herbicides are similar to the natural auxin indole-3-acetic acid (IAA), as most are organic acids containing an aromatic ring and a carboxyl group and characterized by their low molecular weight (George, 1963). Auxinic herbicides are divided into five classes: phenoxy-carboxylic acids (e.g., 2,4-dichlorophenoxyacetic acid); benzoic acids (e.g., dicamba); pyridineacids (e.g., picloram, clopyralid); quinolinecarboxylic acids (e.g., quinclorac); and pyrimidine carboxylic acid (e.g. aminocyclopyrachlor). Structural variation in each herbicide molecule influences binding to receptor proteins (Tan et al., 2007) and the degradation rate within the cell.

Resistance to auxinic herbicides was originally thought to be difficult to evolve for several reasons, including (i) genetic mutations in auxin signalling pathways which would alter the complex signalling network governed by auxin, and thereby decrease survival capacity in harsh environmental conditions (Jasieniuk and Maxwell, 1994; Mortensen et al., 2012); (ii) auxins which affect the dynamics of cellular metabolism at various levels of organization, including specific processes in each cell such as endocytosis, cell polarity, and cell cycle control; and (iii) auxins which also act in regulatory processes at the level of a dynamic biological system, directing macroscopic processes such as embryogenesis, organizational and spatial patterning of tissues, and the formation of new organs (Woodward and Bartel, 2005).

Despite the critical role of auxin signaling in plant development, more than 30 cases of resistance to auxinic herbicides have been reported worldwide (Heap, 2014). The molecular basis of most of the current cases of auxin resistance mechanisms is unknown. In dicamba-resistant Kochia scoparia (Preston et al., 2009), auxinic-herbicide resistant Sinapis arvensis (Zheng and Hall, 2001), and 2,4D resistant Sisymbrium orientale (Preston and Malone, 2014), resistance is conferred by single dominant alleles, indicating that resistance could theoretically evolve and become established more quickly than resistance due to complex genetic inheritance (Jasieniuk and Maxwell, 1994). However, the resistance mechanisms have not yet been elucidated in most cases, despite the discovery of auxin receptors and improved understanding of auxinic herbicide mechanisms of action.

Future progress in understanding the auxin hormone regulation of plant development should lead to improvements in management practices, particularly with regard to new technologies that implement transgenic resistance to auxinic herbicides. Transgenic maize (Zea mays) and soybean (Glycine max) crops with resistance to 2,4-D (Wright et al., 2010) and soybean and cotton (Gossypium hirsutum) crops with resistance to dicamba (Behrens et al., 2007) will soon be marketed. These technolo- 
gies will likely be adopted by growers worldwide over the next five years. Some concerns have been expressed about the use of auxin herbicide resistant transgenic crops, including possible off-target movement of auxinic herbicides to susceptible cultivars and species that may be subjected to application mistakes and herbicide drift (Mortensen et al., 2012).

Many researchers have examined the mechanisms of auxin activity and related scientific advances, but most of them have focused on plant development, such as Badescu and Napier (2006); Tromas et al. (2010); and Sauer et al. (2013). Others have discussed the mechanisms that explain auxin herbicide action when applied in high doses (Grossmann, 2010; Mithila et al., 2011). Adopting a different approach, this text aimed to discuss new research not considered in previous reviews, focusing on how auxin herbicides control weeds and possible new biochemical routes of auxinic herbicide resistance. This review aims to give the reader a new view of how auxins act, analyzing their behavior as a chemical signal that causes drastic changes in cell growth and plant development.

\section{Auxin induced signal transduction}

The cell responses to auxin at the plasma membrane are characterized by fast metabolic reactions due to the existence of a chemical receptor called Auxin Binding Protein 1 (ABP1). This receptor was first identified by Hertel et al. (1972) in maize (Zea mays) coleoptile membranes. Auxin binding to ABP1 in the plasma membrane induces proton pump hyperactivity. ATP synthases (proton pumps) are responsible for keeping the $\mathrm{pH}$ gradient between the apoplast and the symplast. Once accumulation of protons outside the cell is activated, extracellular pH declines (Tromas et al., 2010; Sauer and Kleine-Vehn, 2011). Electrochemical imbalance caused by an Efflux of $\mathrm{H}^{+}$leads to the opening of a potassium channel which pumps potassium into the cell. The increase in $\mathrm{K}^{+}$causes water influx through aquaporins (water-carrier proteins), resulting in an increase in cellular turgidity (Michelet and Boutry, 1995; Maeshima, 2001).

Acidification caused by protons accumulating in the apoplast leads to cell wall hydration (Rayle and Cleland, 1970). Proteins called expansins are activated by acidic conditions in the cell wall, breaking non-covalent bonds between cellulose and hemicellulose (cell wall components) and loosening the cell wall (Wolf et al., 2012). As a consequence of cell wall loosening, the turgor potential (and thus the water potential) drops, causing water uptake and cell expansion.

In this situation, some authors suggest that when cell expansion occurs, calcium osmo-sensitive channels open due to the membrane phospholipid rearrangement caused by the turgor variation (Monshausen and Gilroy, 2009). The increase in $\mathrm{Ca}^{2+}$ halts the expansion of cell walls in two different ways. First, it inhibits the action of ATPases and $\mathrm{H}^{+}$efflux, leading to apoplast alkalization, and inhibits the activity of expansins and other proteins involved in cell expansion. Second, the action of $\mathrm{Ca}^{2+}$ on the enzyme activates phosphatidylinositol-3-phosphate (PtdIns(3)P), which will phosphorylate NADPH oxidase components and produces reactive oxygen species (ROS).

The ABP1 at the plasma membrane also activates a Rho-like small G protein called RAC/ROP GTPase. G proteins have a key role in signal transduction in eukaryotic cells, activating signaling cascades that regulate growth and development (Berken and Wittinghofer, 2008). RAC/ ROPs are specific G proteins from plants that can easily connect to the energy-storing molecules similar to ATP [guanine triphosphate (GTP) and guanine diphosphate (GDP)]. Thus, in the cellular environment, RAC/ROPs are found in three configurations including a free state (without any binding), an active state when connected to GTP, and an inactive state when bound with GDP. Xu et al. (2010) studied specific RAC/ROP GTPases, called ROP2 and RAP6, and found that these proteins which are activated by $\mathrm{ABP} 1$, are important to modulate spatial coordination. RAC/ROP GTPases have an important role in cytoskeleton organization, modeling the structure and arrangement of actin filaments and microtubules.

Auxins also regulate gene expression through TIR (Transport Inhibitor Response)/AFB (auxin-signaling Fbox), F-box protein components of the SCF (Skp, Cullin, F-box) complex ubiquitination pathway. In the plant cell nucleus, there are genes which are only transcriptionally activated in the presence of auxins by transcription factors called ARFs (Auxin response factors). Under normal conditions, the ARFs stay inactive, since they are bound to repressor proteins known as the Aux/IAA transcription factors. To degrade the Aux/IAA repressors and to promote ARF activation, there are protein complexes called SCF $\mathrm{S}^{\mathrm{Tir} / \mathrm{AFB}}$, which participate in a degradation route of proteins known as ubiquitination. The auxin molecule acts as a "glue" making the connection between the SCF Tir/AFB complex and the Aux/IAA (Tan et al., 2007), thereby promoting the degradation of this repressor protein. Degradation of the repressor protein activates the ARFs and transcription of genes related to auxin responses (Badescu and Napier, 2006; Tan et al., 2007; Sauer et al., 2013).

\section{Synthetic auxins as herbicides}

Rahman et al. (2007) observed that 2,4-D has the capacity to remove actin and slow down cytoplasmatic streaming. Recently, Rodríguez-Serrano et al. (2014) discovered that the action of 2,4-D on actin cytoskeleton structures leads to plant epinasty and alteration of the mobility of peroxisomes and mitochondria into cell environments (Figure 1). Because these organelles move along the cytoskeleton, Rodríguez-Serrano et al. (2014) proposed that actin disturbances probably affect the peroxisome and mitochondria metabolism, as they share many metabolites with each other and with chloroplasts. Finally, because peroxisomes are antioxidant organelles, their most important function is to remove 

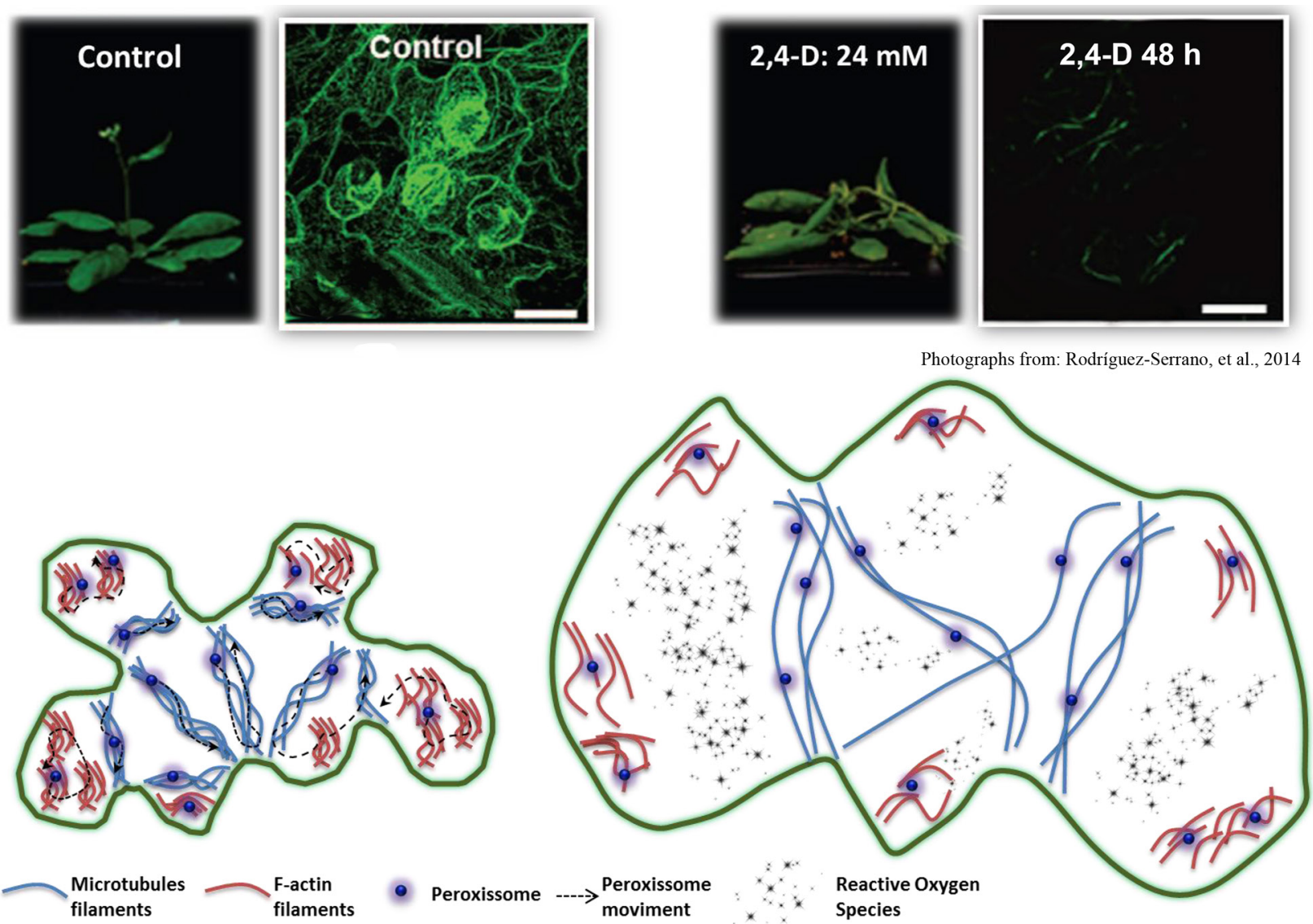

Figure 1 - The photographs represent the cytoskeleton in epidermal cells of Arabidopsis leaves expressing Green Fluorescent Protein Fusion to Actin-Binding Domain 2 (GFP - FABD2), untreated (left) and 2,4-D treated (right) showing the effect of 2,4-D on the cytoskeleton leading to plant epinasty. Bars represent $25 \mu \mathrm{m}$ (Images from: Rodríguez-Serrano, et al., 2014). The schematic drawing (left) represents the normal activity of peroxisome organelles, with a dynamic movement removing reactive oxygen species from different parts of the cell. When auxin are sprayed in high doses (right) the structure and arrangement of actin filaments and microtubules in the peroxisomes antioxidative defense start to have a limited range and slow movement, then the cell enters into severe oxidative stress leading to plasmatic membrane destruction and cell death.

ROS from different parts of the cell. Considering the effect of auxinic herbicides on reducing actin bundling and polymerization, the peroxisomes antioxidative defense starts to have a diminished functionality. Thus, the cell enters a state of severe oxidative stress due to the limitation placed on peroxisomes and the mitochondria function.

Death of most plant tissues treated with 2,4-D is caused by the accumulation of abscisic acid (ABA) and ethylene inducing oxidative stress induced by high ROS production (Grossmann, 2007; 2010). These free radicals are produced by NADPH oxidases in the plasma membrane, which are activated by RAC/ROP (Jones et al., 2007). Yu et al. (2012) used Arabidopsis thaliana (Arabidopsis) mutants and confirmed the importance of RAC/ ROPs activity as modulators of auxin responses. Furthermore, Yu et al. (2012) found a connection between auxin and ABA responses, where a phosphatase protein present in the ABA signaling pathway binds to ROP. This binding inhibits the protein kinase SNF1 (a protein re- lated to kinase 2 (SnRK2)), which measures the ROS production related to the ABA responses (stomatal closure, inhibition of cell growth, and cell death).

To summarize the process: auxin first acts on plasma membrane activating ABP1 (Rodríguez-Serrano et al., 2014), altering the cytoskeleton and, consequently, reducing the peroxisomes' antioxidative defense. Next, the second process (Grossmann, 2007; 2010) acts by TIR/ AFB ubiquitinatin route, in which ABA and ethylene biosynthesis genes are activated leading to ROS overproduction that induces changes in intracellular redox status, making it an oxidizing environment (electron acceptor) that affects the activity or synthesis associated with redox systems. Initially, the main system that is changed by high ROS production is the cell wall. Peroxidases and $\mathrm{H}_{2} \mathrm{O}_{2}$ (hydrogen peroxide) cause cell wall reorganization, in particular the expansin interconnection (proteins that exist in high amounts in the cell walls), that include the matrix dehydration and saturation of the wall, which leads to the hardening and slowing of cell growth (Pereira 
et al., 2011). Due to the loss of cell wall structure, ROS are able to penetrate deep into the plasma membrane where they can interact with phospholipids promoting: (i) unsaturation of plasma membrane lipids, (ii) leakage of the cytosol, and (iii) cell death.

\section{Protein degradation regulated by SKP2A}

Plant development is governed by three important processes: cell division, cell expansion, and cell differentiation (Coffman, 2004). Auxins represent a group of hormones that regulate virtually all these basic cellular processes. Recently, a new signaling route induced by auxin was discovered in the cell division process. This is a new pathway for protein degradation, regulated by another SCF-dependent proteasomal ubiquitin-dependent protein. Pozo et al., (2002; 2006) identified the F-box protein (S-Phase Kinase-Associated Protein 2A) SKP2A acting as a regulator of cell division.

The $\mathrm{SCF}^{\mathrm{SKP2A}}$ complex regulates two transcription factors, E2FC and DPB (cyclin-dependent kinases in the retinoblastoma pathway) by promoting their degradation (Figure 2). These factors regulate the expression of genes required for progressing the cell cycle, allowing cells to move from the G1 phase (protein synthesis and growth) to DNA duplication phase (S) (Gutierrez et al., 2002; De Veylder et al., 2003; Dewitte and Murray, 2003). When E2FC and DPB factors are degraded, the plant cell halts its cycle and remains in the G1 phase.

Transgenic Arabidopsis plants that over-express the transcription factors DPB and E2FC in a stabilized form (resistant to SCF ${ }^{\text {SKP2A }}$ - mediated degradation) demonstrated their large influence in plant development (Pozo et al., 2002; 2006). Specifically, morphological changes relative to wild plants were observed, including severe developmental defects. The down regulation of E2FC in Arabidopsis had significant impacts on plant growth resulting in dwarf plants with curved, deformed leaves with a wavy appearance (Figure 2). From these results, it was concluded that a co-expression regulation between the DPB and E2FC factors is necessary to maintain a properly functioning cell cycle.

Jurado et al. (2010) used crystallographic studies of the SKP2A structure to identify a binding site where auxins can bind directly. Furthermore, it was concluded that auxins regulate degradation promoted by SKP2A to the E2FC transcription factors E2FC and DPB. Another

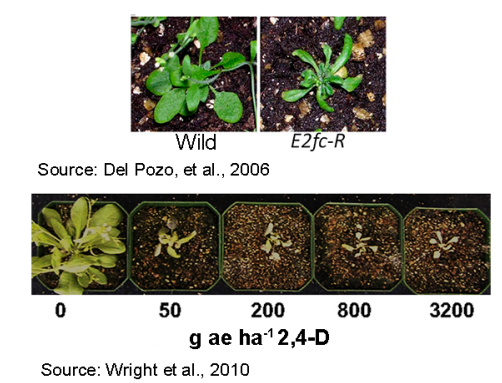

Source: Wright et al., 2010
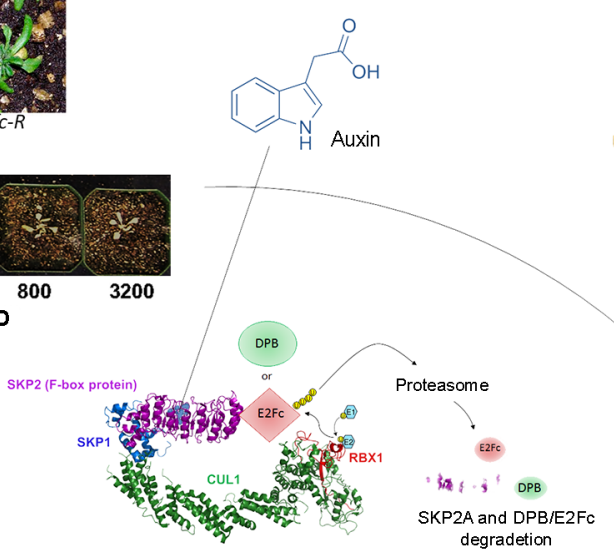
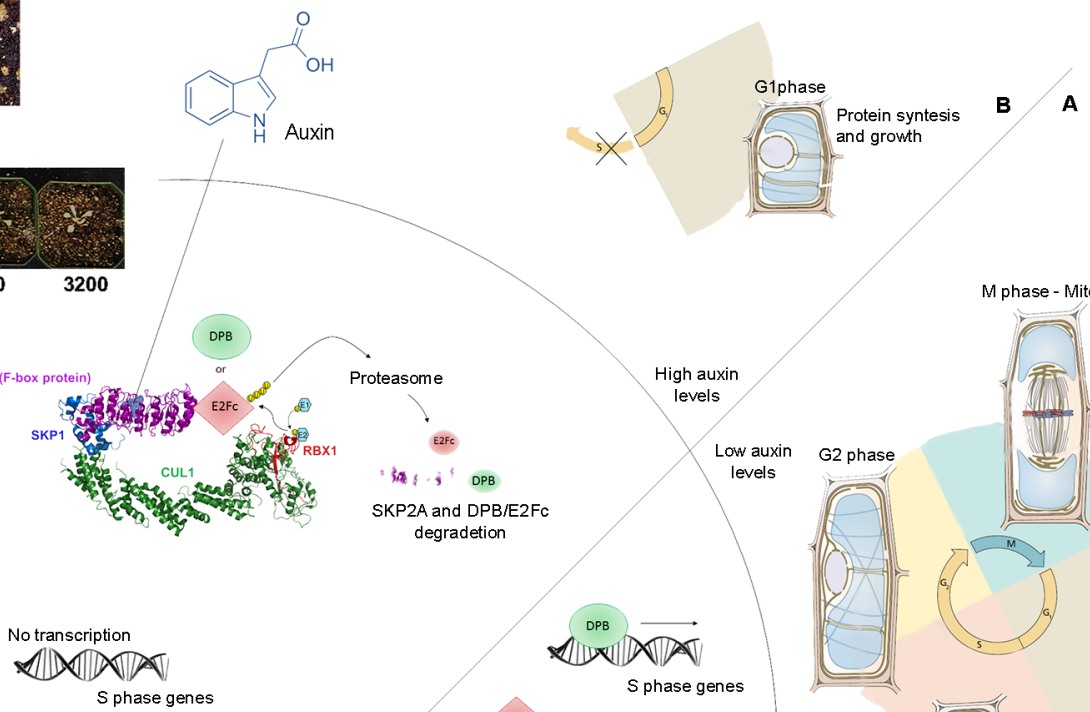

$S$ phase genes

Source: Zheng, et al., 2002

A
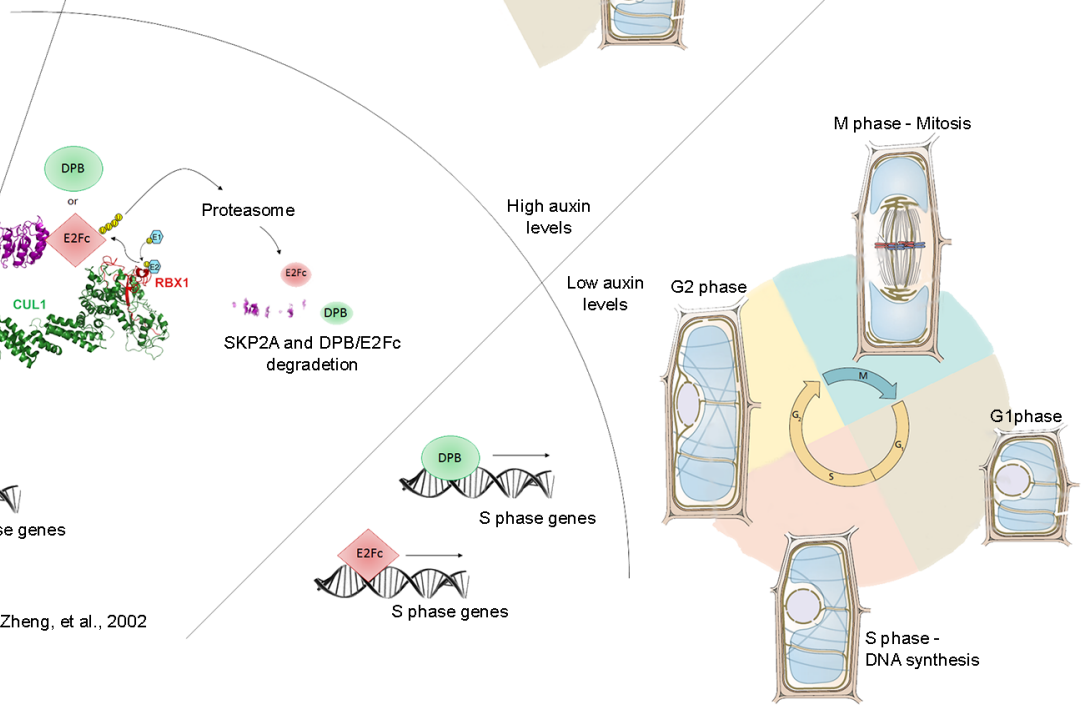

Source: Taiz and Zaiger, 2013

Figure 2 - Model of SCFSKP2A auxin signaling. SKP2A (S-Phase Kinase-Associated Protein 2A) is an F-box protein that is activated by auxin. A) At low levels of auxin, DPB and E2Fc (cyclin-dependent kinases in the retinoblastoma pathway) regulate the expression of genes required for cell cycle progress, allowing the cell to move from the G1 phase (protein synthesis and growth) to the DNA duplication phase (S). B) At high levels of auxin, SCF ${ }^{\text {KKPAA }}$ induces E2FC, DPB and SKP2A degradation. The plant cell then halts its cycle, remaining in the G1 phase. C) A compilation of E2FC Arabidopsis (Arabidopsis thaliana) mutant phenotype and 2,4-D herbicide symptoms, cause similar defects in plant development. A new possibility of weed resistance mechanism involving this pathway is an SKP2A binding restriction site to synthetic auxins, which prevents transcriptional factor degradation. (Figure Scheme Adapted from Santner et al., 2009. Images: Cell division: Taiz and Zaiger, 2013. SCFSKP2A: Zheng, et al., 2002. E2fc Arabidopsis mutant: Pozo, et al., 2006 and 2,4-D herbicide symptoms: Wright et al., 2010. 
interesting aspect described by Jurado et al. (2010) was that when there are high levels of cellular auxin, selfdegradation of SKP2A occurs together with transcription factors. Natural and synthetic auxins have different capabilities related to SKP2A degradation, which demonstrate the importance of auxins in regulating the functions of cell division and in illustrating the minute control of the SKP2A, E2FC and DPB degradation pathway. Any deviation in the performance of these proteins or in the auxin levels in the cell can affect the entire homeostasis of the cell cycle.

\section{New Perspectives on Auxinic Herbicide Resistance}

Given the recently discovered concepts for auxin pathways, new perspectives can be considered for how weeds may evolve resistance to auxinic herbicides. There are now multiple known mechanisms through which auxinic herbicides may act. The new discoveries described above suggest additional possibilities for the evolution of auxinic herbicide resistance mechanisms.

\section{TIR / AFBs and ABP1}

The mechanisms of ABP1 action and its role in weed resistance are important, but poorly understood. Comparing resistant and susceptible biotypes of wild mustard (Brassica kaber), two binding sites in ABP1 were found in the susceptible biotypes, one with a high affinity and another with a low affinity for auxin. There was only one binding site with low auxin affinity in the resistant biotype. As a result, auxin responses at the membrane level were lower in resistant biotype, including slower cell expansion in the absence of auxin. On the other hand, the susceptible biotype had normal growth (Webb and Hall, 1995; Mithila and Hall, 2005).

Unlike ABP1, the SCF TIR/AFB mechanisms of resistance are being examined in the role of the Arabidopsis mutations in TIR/AFB that confer resistance on different synthetic auxins. Walsh et al. (2006) studied distinct mutants associated with the $\mathrm{SCF}^{\mathrm{TIR} / \mathrm{AFB}}$ pathway and suggested the existence of significant differences in the chemical perception of synthetic auxins within upstream components of the pathway. These were confirmed by Calderón-Villalobos et al. (2012) who characterized Aux/IAA instability associated with different co-receptors TIR/AFB, using either natural or synthetic auxins. The binding between TIR and AUX/IAA showed a high binding affinity for IAA, 1-NAA and 2,4-D; however, for picloram there was weaker binding activity to the SCF ${ }^{\mathrm{TIR} 1}$ complex. Gleason et al. (2011) found that 2,4$\mathrm{D}$ and dicamba have different requirements for binding the F-box complex receptor. The mutants that were TIR 1 and AFB5 defective conferred resistance on dicamba, but only the tir1-1 mutant was resistant to 2,4-D. Considering these items of information together, it seems likely that synthetic auxin herbicides that act on multiple pathways upstream of SCF ${ }^{\mathrm{TIR} / \mathrm{AFB}}$ may have a reduced chance of evolving resistance compared to auxin herbicides that have a single site of action.
For the two receptors that auxin binds, ABP1 has a fundamental role in repressing $S C F^{T I R} / A F B$ and, therefore, affects ABA overproduction (Tromas et al., 2010). One must consider that both ABP1 and SCF TIR/AFB have a determinant role in activating the cell death process, despite the fact that they repress each other. Changes in the auxin binding sites of these two receptors could confer resistance on auxinic herbicides. Most of the mutations in the polypeptides that encode SCF TIR/AFB and $\mathrm{ABP} 1$ result in plants with less ability to compete in the environment and some mutations in ABP1 induce fatality (Jasieniuk et al., 1995; Chen et al., 2001). These fitness costs of potential resistance mutations may explain why fewer cases of resistance to synthetic auxins have been discovered relative to other herbicide mode of action groups (Wright et al., 2010; Mithila et al., 2011).

SKP2A

The SCF ${ }^{\mathrm{SKP2A}}$ complex represents a new site for the possible evolution of auxinic herbicide resistance. Jurado et al. (2010) evaluated the effect of low 2,4-D concentrations in Arabidopsis mutants for SKP2A and found less of an effect on root growth inhibition in the mutants compared to wild plants. In addition, Jurado et al. (2010) produced a double mutant for TIR1 and SKP2A, resulting in greater resistance to 2,4-D.

We propose a new resistance mechanism associated with this route because of the evidence that SKP2A is a positive regulator of auxin responses and that it interacts with TIR1. Since SKP2A regulates the transcription factors E2FC and DPB, it is possible to keep the proportions between these two factors in favorable quantities for proper development of the cell cycle. As a result of mutations, plants could evolve mechanisms to restrict the binding site of a given synthetic auxin, preventing its direct connection to SKP2A.

Another possible mechanism for consideration is that SKP2A has the ability to self-degrade together with the transcription factors to which it is connected. Since SKP2A has higher stability when connected to synthetic auxin than to IAA, it is expected that plants treated with synthetic auxins will develop intense defects in their development when further degradation of transcription factors (E2FC and DPB) occurs. Eventually, the culmination of these defects results in tissue and plant death. A possible resistance mechanism could involve accelerating SKP2A self-degradation, keeping the levels of E2FC and DPB balanced. Such accelerated self-degradation could proceed via several routes, such as increased SKP2A ubiquitination or SKP2A transcript silencing.

\section{Final Remarks}

The current knowledge of the mode of action followed by auxins can give clues to determining the characterization of the kind of resistance occurring in the field. Auxinic herbicide resistance can be induced in two 
areas: one in plasma membrane and the other in transcription ARFs. When a resistant plant suffers only tissue oxidation without epinasty, then resistance is likely to be due to changes in $\mathrm{ABP} 1$; however, if resistant plants show epinasty without strong tissue necrosis, it means that complex SCF $\mathrm{SCIR}^{\mathrm{TI} A \mathrm{ABB}}$ is in the process of destroying AUX / IAA, so there may be changes to this enzymatic complex that are preventing the herbicide thus making the connection between TIR1 or AFBs and Aux / IAA.

Substantial progress has recently been made in understanding auxin mechanisms of action. Many questions still remain about the mechanisms of auxin action, and there is still much more to understand about the routes involving TIR/AFB, ABP1, and SKP2A. In the near future it may be possible to understand the interactions between the numerous receptors and co-receptors activated by a single signaling molecule, and how these are coordinated. This will lead to a greater understanding of the changes and adjustments in this complex signaling a network that could potentially confer higher survival under selection with auxinic herbicides and lead to resistance evolution. Understanding these currently unknown aspects of auxin action will help to address the numerous and difficult challenges that agriculture will have to face in the future.

\section{References}

Badescu, G.O.; Napier, RM. 2006. Receptors for auxin: will it all end in TIRs? Trends in Plant Science 11: 217-223.

Behrens, M.R.; Mutlu, N.; Chakraborty, S.; Dumitru, R.; Jiang, W.Z.; LaVallee, B.J.; Herman, P.L.; Clemente, T.E., Weeks, D.P. 2007. Dicamba resistance: enlarging and preserving biotechnology-based weed management strategies. Science 316: 1185-1188.

Berken, A.; Wittinghofer, A. 2008. Structure and function of Rho-type molecular switches in plants. Plant Physiology and Biochemistry 46: 380-393.

Calderón-Villalobos, L.I.; Lee, S.; Oliveira, C.; Ivetac, A.; Brandt, W.; Armitage, L.; Sheard, L.B.; Tan, X.; Parry, G.; Mao, H. 2012. A combinatorial TIR1/AFB-Aux/IAA co-receptor system for differential sensing of auxin. Nature Chemical Biology 8: 477-485.

Chen, J.G.; Ullah, H.; Young, J.C.; Sussman, M.R.; Jones, A.M. 2001. ABP1 is required for organized cell elongation and division in Arabidopsis embryogenesis. Genes and Development 15: 902-911.

Coffman, J.A. 2004. Cell cycle development. Developmental Cell 6: 321-327.

De Veylder, L.; Joubes, J.; Inze, D. 2003. Plant cell cycle transitions. Current Opinion in Plant Biology 6: 536-543.

Dewitte, W.; Murray, J.A. 2003. The plant cell cycle. Annual Review of Plant Physiology and Plant Molecular Biology 54: 235-264.

George, E.F. 1963. Plant Propagation by Tissue Culture. 3ed. Springer, Berlin, Germany. p. 115-173.

Gleason, C.; Foley, R.C.; Singh, K.B. 2011. Mutant analysis in arabidopsis provides insight into the molecular mode of action of the auxinic herbicide dicamba. PLoS ONE 6: E17245.
Grossmann, K., 2007. Auxin herbicide action: lifting the veil step by step. Plant Signaling \& Behavior 2: 421-425.

Grossmann, K. 2010. Auxin herbicides: current status of mechanism and mode of action. Pest Management Science 66: 113-120.

Gutierrez, C.; Ramirez-Parra, E.; Castellano, M.M.; Pozo, J.C. 2002. G(1) to $S$ transition: More than a cell cycle engine switch. Current Opinion in Plant Biology 5: 480-486.

Hertel, R.; Thomson, K.S.; Russo, V.E.A. 1972. In-vitro auxin binding to particulate cell fractions from corn coleoptiles. Planta 107: 325-340.

Heap, I. 2014. The international survey of herbicide resistant weeds. Available at: www.weedscience.org [Accessed Dec. 9, 2014]

Jasieniuk, M.; Maxwell, B.D. 1994. Population genetics and the evolution of herbicide resistance in weeds. Phytoprotection 75 (suppl.): 25-35.

Jasieniuk, M.; Morrison, I.N.; Brule-Babel, A.L. 1995. Inheritance of dicamba resistance in wild mustard (Brassica kaber). Weed Science 43: 192-195.

Jones, M.A.; Raymond, M.J.; Yang, Z.; Smirnoff, N. 2007. NADPH oxidase-dependent reactive oxygen species formation required for root hair growth depends on ROP GTPase. Journal of Experimental Botany 58: 1261-1270.

Jurado, S.; Abraham, Z.; Manzano, C.; López-Torrejón, G.; Pacios, L.F.; Pozo, J.C. 2010. The Arabidopsis cell cycle F-box protein SKP2A binds to auxin. Plant Cell 22: 3891-3904.

Michelet, B.; Boutry, M. 1995. The plasma membrane $\mathrm{H}+$ ATPase (a highly regulated enzyme with multiple physiological functions). Plant Physiology 108: 1-6.

Maeshima, M. 2001. TONOPLAST TRANSPORTERS: Organization and function. Annual Review of Plant Physiology and Plant Molecular Biology 52: 469-497.

Mithila, J.; Hall, J.C. 2005. Comparison of ABP1 over-expressing Arabidopsis and underexpressing tobacco with an auxinic herbicide-resistant wild mustard (Brassica kaber) biotype. Plant Science 169: 21-28.

Mithila, J.; Hall, J.C.; Johnson, W.G.; Kelley, K.B.; Riechers, D.E. 2011. Evolution of resistance to auxinic herbicides: historical perspectives, mechanisms of resistance, and implications for broadleaf weed management in agronomic crops. Weed Science 59: 445-457.

Monshausen, G.B; Gilroy, S. 2009. Feeling green: mechanosensing in plants. Trends in Cell Biology 19: 228-235.

Mortensen, D.A.; Egan, J.F.; Maxwell, B.D.; Ryan, M.R.; Smith, R.G. 2012. Navigating a critical juncture for sustainable weed management. BioScience 62: 75-84.

Pereira, C.S.; Ribeiro, J.M.; Vatulescu, A.D.; Findlay, K.; MacDougall, A.J.; Jackson, P.A. 2011. Extensin network formation in Vitis vinifera callus cells is an essential and causal event in rapid and $\mathrm{H} 2 \mathrm{O} 2$-induced reduction in primary cell wall hydration. BMC Plant Biology 11: 106.

Pozo, J.C.; Boniotti, M.B.; Gutierrez, C. 2002. Arabidopsis E2F2 functions in cell division and is degraded by the ubiquitinSCFAtSKP2 pathway in response to light. Plant Cell 14: 30573071.

Pozo, J.C.; Diaz-Trivino, S.; Cisneros, N.; Gutierrez, C. 2006. The balance between cell division and endoreplication depends on E2FC-DPB, transcription factors regulated by the ubiquitinSCFSKP2A pathway in Arabidopsis. Plant Cell 18: 2224-2235. 
Preston, C.; Belles, D.S.; Westra, P.H.; Nissen, S.J.; Ward, S.M. 2009. Inheritance of resistance to the auxinic herbicide dicamba in Kochia (Kochia scoparia). Weed Science 57: 43-47.

Preston, C.; Malone, J.M. 2014. Inheritance of resistance to 2,4$\mathrm{D}$ and chlorsulfuron in a multiple resistant population of Sisymbrium orientale. Pest Management Science DOI: 10.1002/ ps.3956

Rahman, A.; Bannigan, A.; Sulaman, W.; Pechter, P.; Blancaflor, E.B.; Baskin, T.I. 2007. Auxin, actin and growth of the Arabidopsis thaliana primary root. The Plant Journal 50: 514528.

Rayle, D.L. and Cleland, R.E., 1970. Enhancement of wall loosening and elogantion by acid solutions. Plant Physiology, 46:250-3.

Rodríguez-Serrano, M.; Pazmiño, D.M.; Sparkes, I.; Rochetti, A.; Hawes, C.; Romero-Puertas, M.C.; Sandalio, L.M. 2014. 2,4-Dichlorophenoxyacetic acid promotes S-nitrosylation and oxidation of actin affecting cytoskeleton and peroxisomal dynamics. Journal of Experimental Botany 237: 1-11.

Santner, A.; Calderon-Villalobos, L.I.A.; Estelle, M. 2009. Plant hormones are versatile chemical regulators of plant growth. Nature Chemical Biology 5: 301-307.

Sauer, M.; Kleine-Vehn, J. 2011. AUXIN BINDING PROTEIN1: the outsider. The Plant Cell 23: 2033-2043.

Sauer, M.; Robert, S.; Kleine-Vehn, J. 2013 Auxin: simply complicated. Journal of Experimental Botany 64: 2565-2577.

Taiz, L.; Zeiger, E. 2013. Plant Physiology = Fisiologia Vegetal. 5ed. Artmed, Porto Alegre, RS, Brazil (in Portuguese).

Tan, X.; Calderon-Villalobos, L.I.; Sharon, M.; Zheng, C.; Robinson, C.V.; Estelle, M.; Zheng, N. 2007. Mechanism of auxin perception by the TIR 1 ubiquitin ligase. Nature 446: 640-645.

Tromas, A.; Paponov, I.; Perrot-Rechenmann, C. 2010 AUXIN BINDING PROTEIN 1: Functional and evolutionary aspects. Trends in Plant Science 15: 436-446.
Walsh, T.A.; Neal, R.; Merlo, A.O.; Honma, M.; Hicks, G.R.; Wolff, K.; Matsumura, W.; Davies. J.P. 2006. Mutations in an auxin receptor homolog AFB5 and in SGT1b confer resistance to synthetic picolinate auxins and not to 2,4-dichlorophenoxyacetic acid or indole-3-acetic acid in Arabidopsis. Plant Physiology 142: 542-552.

Webb, S.R.; Hall, J.C. 1995. Auxinic herbicide-resistant and herbicide-susceptible wild mustard (Sinapis arvensis L.) biotypes: effect of herbicides on seedling growth and auxinbinding activity. Pesticide Biochemistry and Physiology 52: 137148.

Wright, T.R.; Shan, G.; Walsh, T.A.; Lira, J.M.; Cui, C.; Song, P.; Zhuang, M.; Arnold, N.L.; Lin, G.; Russell, S.M.R.; Cicchillo, M.; Peterson, M.A.; Simpson, D.M.; Zhou, N.; Ponsamuel, J.; Yau, K.; Zhang, Z. 2010. Robust crop resistance to broadleaf and grass herbicides provided by aryloxyalkanoate dioxygenase transgenes. Proceedings of the National Academy of Sciences 107: 20240-20245.

Wolf, S.; Hématy, H.; Herman; K. 2012. Growth control and cell wall signaling in plants. Annual Review of Plant Biology 63: 381-407.

Woodward, A.W.; Bartel, B. 2005. Auxin: regulation, action, and interaction. Annals of Botany 95: 707-735.

Yu, F.; Qian, L.; Nibau, C.; Duan, Q.; Kita, D.; Levasseur, K.; Li, X.; Lu, C.; Li, H.; Hou, C. 2012. FERONIA receptor kinase pathway suppresses abscisic acid signaling in Arabidopsis by activating ABI2 phosphatase. Proceedings of the National Academy of Sciences 109: 14693-14698.

Xu, T.; Wen, M.; Nagawa, S.; Fu, Y.; Chen, J.G.; Wu, M.J.; PerrotRechenmann, C.; Friml, J.; Jones, A.M.; Yang, Z. 2010. Cell surface- and rho GTPase-based auxin signaling controls cellular interdigitation in Arabidopsis. Cell 143: 99-110.

Zheng, H.G.; Hall, J.C. 2001. Understanding auxinic herbicide resistance in wild mustard: physiological, biochemical, and molecular genetic approaches. Weed Science 49: 276-281. 